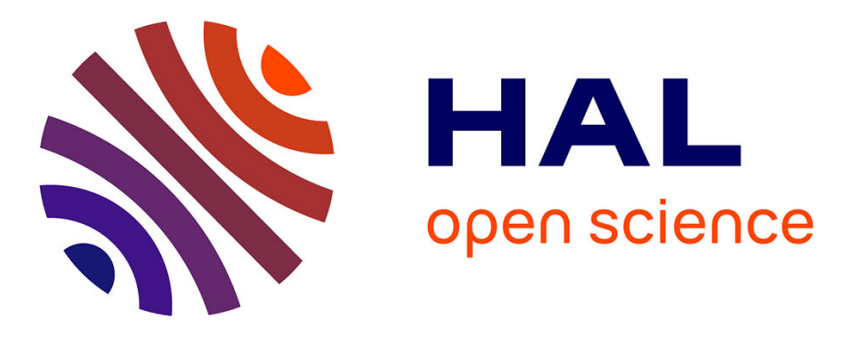

\title{
Directly-modulated IM/DD OFDM transmission over 100-km SSMF using SSB filtering with two silicon micro-ring resonators
}

Mohamed E Chaibi, Karim Hassan, Laurent Bramerie, Christophe Peucheret

\section{- To cite this version:}

Mohamed E Chaibi, Karim Hassan, Laurent Bramerie, Christophe Peucheret. Directly-modulated IM/DD OFDM transmission over 100-km SSMF using SSB filtering with two silicon micro-ring resonators. Conference on Lasers and Electro-Optics (CLEO 2017), Optical Society of America, May 2017, San Jose, California, United States. pp.STu1M.4, 10.1364/CLEO_SI.2017.STu1M.4 . hal01541218

\author{
HAL Id: hal-01541218 \\ https://hal.science/hal-01541218
}

Submitted on 18 Jun 2017

HAL is a multi-disciplinary open access archive for the deposit and dissemination of scientific research documents, whether they are published or not. The documents may come from teaching and research institutions in France or abroad, or from public or private research centers.
L'archive ouverte pluridisciplinaire HAL, est destinée au dépôt et à la diffusion de documents scientifiques de niveau recherche, publiés ou non, émanant des établissements d'enseignement et de recherche français ou étrangers, des laboratoires publics ou privés. 


\title{
Directly-modulated IM/DD OFDM Transmission over 100-km SSMF using SSB Filtering with Two Silicon Micro-ring Resonators
}

\author{
Mohamed-E. Chaibi $^{1 *}$, Karim Hassan ${ }^{2}$, Laurent Bramerie ${ }^{1}$, and Christophe Peucheret ${ }^{1}$ \\ 1- FOTON Laboratory, CNRS UMR 6082, University of Rennes 1, ENSSAT, F-22300 Lannion, France \\ 2- University Grenoble-Alpes, CEA, LETI, MINATEC Campus, F-38054 Grenoble, France \\ *haibi@enssat.fr
}

Abstract: Optical single sideband signals generation using two silicon micro-ring resonators is demonstrated for 5.3-GHz wideband OFDM modulation. Transmission at $14.69 \mathrm{~Gb} / \mathrm{s}$ over $100-\mathrm{km}$ SSMF is made possible thanks to the SSB filtering provided by the MRRs.

\section{Introduction}

OCIS codes: (060.4510) Optical communications; (130.3120) Integrated optics devices; (130.7408) Wavelength filtering devices.

All optical access network standards released so far are based on intensity modulation (IM) at the transmitter side and direct detection at the receiver side with traditional non-return-to-zero (NRZ) modulation format. In practical implementations, directly modulated lasers (DMLs), typically distributed feedback (DFB) lasers, and electro-absorption modulated lasers (EMLs) are commonly used to perform electro-optical conversion. In spite of their simplicity and cost effectiveness, IM/DD systems incorporating DMLs and EMLs are unable to provide high bit-rates over long distances as required to fulfill the needs of future access networks, as a result of fibre group-velocity dispersion. Consequently, the latest 40-Gb/s next-generation passive optical network (NG-PON2) standard is oriented towards wavelength division multiplexing (WDM) solutions consisting in multiplexing four 10-Gb/s NRZ modulated channels [1]. Increasing the number of WDM channels to provide higher bit-rates than NG-PON2 is however not preferred because of the requirement for transceivers with highly accurate wavelength detuning and colourless operation [1]. To achieve higher bit-rates, it is essential to increase the bit-rate per WDM channel beyond $10 \mathrm{~Gb} / \mathrm{s}$. Even if the alreadydeployed bandwidth-limited transceivers are kept, such an objective could still be reached thanks to the use of highly spectrally-efficient multi-carrier modulation formats, such as orthogonal frequency division multiplexing (OFDM). When used in a direct-detection compatible way, such formats are however well known to suffer from dispersioninduced power fading, unless single sideband (SSB) modulation is used [2]. While SSB signals can be generated from complex in-phase and quadrature (IQ) external modulators, this solution results in footprints and power consumptions that are incompatible with access systems. Consequently some reliable and cost-effective methods to synthesise SSB OFDM signals from DMLs are sought.

In this work we report on the use of a DML followed by two micro-ring resonators (MRRs) in series to generate SSB optical signals for wide-band OFDM modulating signals. The SSB filtering allows transmission of a 14.69-Gb/s OFDM signal over 100-km standard single-mode fibre (SSMF).

\section{Principle of the technique}

The use of a single MRR at the output of a DML to reject one of the modulated sidebands has been extensively reported. However, the Lorentzian-shaped transfer function of the MRR has limited its use as a narrow-band filter acting far away from the optical carrier. Optical filters with sufficient rejection based on MRRs in series have been very recently proposed [3], where the effectiveness of the approach was only demonstrated based on measurements of the small-signal frequency response of a dispersive channel. In this work, a two-MRR structure is designed and fabricated on a 220/100 $\mathrm{nm}$ rib waveguide with $200 \mathrm{~mm}$ SOI wafers to provide wide band-rejection, steep transition and high suppression ratio to be used in the large-signal regime with wideband OFDM modulation. Fig. 1 shows the measured transfer functions of the 2 MRRs in series for different detuning values $(\Delta \lambda)$ between the two resonance wavelengths. For a rejection ratio of $12 \mathrm{~dB}$, the proposed structure presents a $13.45-\mathrm{GHz}$ wide rejection band (at $\Delta \lambda=68 \mathrm{pm})$.

\section{Experimental setup}

The experimental setup used to generate an SSB optical signal with the two-MRR structure is depicted in Fig. 4. The modulating signal consists of 300 OFDM symbols distributed over 111 out of a total of 128 subcarriers modulated with 


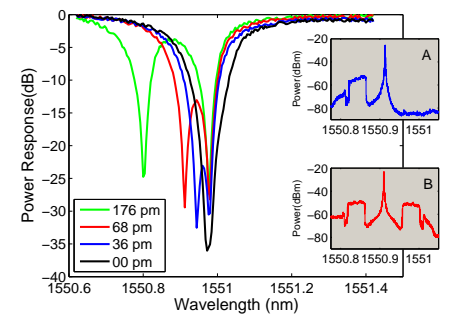

Fig. 1: MRRs transfer functions and optical SSB (A) and DSB (B) OFDM spectra.

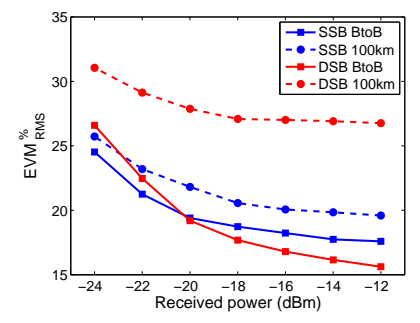

Fig. 2: SSB and DSB performancer after 100-km SSMF.

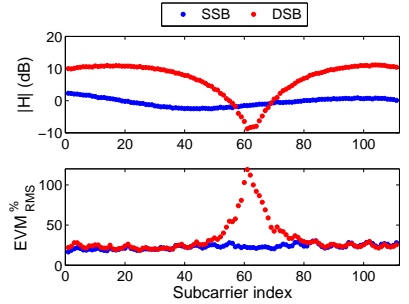

Fig. 3: EVM and channel response after 100-km SSMF.

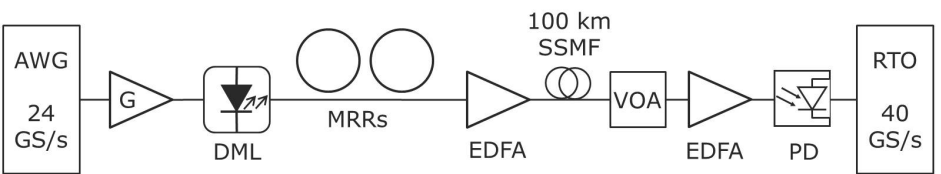

Fig. 4: Experimental setup. AWG:arbitrary waveform generator. SSMF:standard single mode fiber. EDFA:erbium-doped fiber amplifier.

circular 8-state quadrature amplitude modulation (8-QAM) and 8 samples used as cyclic prefix. The digital samples are up-sampled by a factor of 4 to match the $24 \mathrm{GS} / \mathrm{s}$ sampling frequency of the digital-to-analog converter (DAC) before being digitally up-converted to $9 \mathrm{GHz}$. The analogue OFDM signal occupies the frequency band 6.1-11.4 GHz, allowing an overall bit-rate of $14.69 \mathrm{~Gb} / \mathrm{s}$. It is amplified and then used to modulate a 20-GHz bandwidth DFB laser whose linewidth enhancement factor and (adiabatic chirp) corner frequency are measured at 3.8 and $6.46 \mathrm{GHz}$, respectively. The emitting wavelength of the DFB laser and the resonance wavelength of one of the two MRRs are tuned so that one of the two sidebands is suppressed. The optical signal is then boosted and transmitted over 100-km SSMF. Given the chirp properties of the DFB laser, the chosen span is long enough to illustrate the benefit of SSB modulation over double sideband (DSB) modulation [4]. At the receiver side, a variable optical attenuator (VOA) is inserted at the input of the optical preamplifier. After photo-detection (PD), a real-time oscilloscope (RTO) implements analog-to-digital conversion at a 40-GS/s sampling frequency. The OFDM signals are then processed offline using Matlab.

\section{Results and discussions}

The spectra of the generated SSB and DSB signals are shown as insets A and B in Fig. 1, respectively. The latter is measured directly at the output of the DML. While the symmetry of the DSB spectrum is remarkable, the upper sideband of the SSB signal is completely eliminated with a sideband power ratio (SBPR) exceeding $27.4 \mathrm{~dB}$ for all modulating frequencies. The transmission performance in terms of error vector magnitude (EVM) for both SSB and DSB signals is shown in Fig. 2. In the back-to-back configuration, the DSB signal outperforms slightly the SSB one for received powers higher than $-20 \mathrm{dBm}$. This is due to the $3-\mathrm{dB}$ power gain obtained when detecting the two sidebands. After 100-km IM/DD propagation, the SSB signals provide better performance than DSB with EVM values lower than $23.44 \%$, corresponding to a bit error rate of $3.8 \times 10^{-3}$ for received powers higher than $-22 \mathrm{dBm}$. To highlight the origin of the degradation seen in the DSB case after 100-km with respect to the back-to-back configuration, Fig. 3 shows the channel response and the EVM per OFDM subcarrier for $-14 \mathrm{dBm}$ received power. While the SSB signal results in a relatively flat channel frequency response, the presence of channel fading is clear with the DSB signal. The affected OFDM subcarriers exhibit high EVM values exceeding 100\%. On the other hand, the EVM is kept below $26 \%$ for all OFDM subcarriers with SSB signals.

\section{Conclusion}

We reported on the use of a two-MRR structure in series to generate SSB optical signals for OFDM modulation. The feasibility of the approach is demonstrated for 5.3-GHz bandwidth OFDM modulating signals. Transmission at $14.69 \mathrm{~Gb} / \mathrm{s}$ over $100-\mathrm{km}$ SSMF using IM/DD is successfully demonstrated.

\section{Acknowledgments}

This work was supported by the European Commission's 7th Framework Programme through the SEQUOIA project (grant agreement no. 619626).

\section{References}

1. D. Nesset, J. Lightw. Technol. 33, 1136-1143 (2015).

2. B. J. C. Schmidt et al., J. Lightw. Technol. 26, 196-203 (2008).

3. S. X. Chew et al., J. Lightw. Technol. 34, 4705-4714, (2016).

4. L. Bjerkanet et al., J. Lightw. Technol. 14, 839-850 (1996). 